\title{
Klinefelter Syndrome and Corpus Callosum Agenesis
}

\author{
Indar Kumar Sharawat ${ }^{1}$ Prateek Kumar Panda ${ }^{1}$
}

Received: 23 March 2020 / Accepted: 16 April 2020 / Published online: 8 May 2020

(C) Dr. K C Chaudhuri Foundation 2020

To the Editor: A 5-mo-old male infant was brought by parents as the antenatal ultrasound at $26 \mathrm{wk}$ of gestation detected agenesis of corpus callosum and dilatation of bilateral lateral ventricles. This pregnancy was the first conception for the mother. It was a booked pregnancy with normal antenatal and perinatal periods. Routine antenatal investigations including the TORCH profile were normal. History for drug intake, antepartum hemorrhage, febrile illness, and radiation exposure, was negative. He was born at term with a birth weight of $3.2 \mathrm{~kg}$. Physical examination at one month was unremarkable, except for slight axial and appendicular hypotonia. MRI brain confirmed fetal ultrasonography findings and revealed corpus callosal agenesis, dilatation of bilateral lateral ventricles with colpocephaly. Skeletal X-rays, ultrasonography of abdomen and echocardiogram were unremarkable. Karyotyping revealed 47, XXY karyotype, suggestive of Klinefelter syndrome (KS).

Hypoplasia or agenesis of the corpus callosum in children with KS rarely reported. In the published literature there is one case each of corpus callosum agenesis in a child of KS with co-existing Aicardi syndrome [1] and Schinzel-Giedion syndrome [2]. The index case did not have any seizures, chorioretinal/skeletal abnormalities or typical facial features suggestive of Schinzel-Giedion syndrome. The other two reports of corpus callosum hypoplasia in children with KS were in those with 49, XXXY karyotype reported by Hoffman et al. [3]. One child also had diffuse cerebral and cerebellar atrophy with scattered punctate foci of $\mathrm{T} 2$ signal hyperintensity in the white matter. However, in our case apart from mild dilatation of lateral ventricles, colpocephaly and agenesis of the corpus callosum, no other neuroimaging abnormalities were present.

Prateek Kumar Panda

drprateekpanda@gmail.com

1 Pediatric Neurology Division, Department of Pediatrics, All India Institute of Medical Sciences, Rishikesh, Uttarakhand 249203, India
They believed that these white matter lesions may be part of the clinical spectrum of this syndrome. Adverse effects of sex chromosome polysomy on brain development manifesting as a learning disability, subaverage cognitive performance, motor dyspraxia, and behavioral/neuropsychiatric abnormalities may correlate with these white matter abnormalities [4, 5]. The advancement in prenatal screening has increased the early detection of congenital malformations and coexisting genetic syndromes. Prospective longitudinal studies with appropriate imaging modalities and neurological assessment can determine the significance of these neuroimaging abnormalities.

\section{Compliance with Ethical Standards}

Conflict of Interest None.

\section{References}

1. Keith CG. The concurrence of Aicardi and Klinefelter syndromes. Pathology. 1980;12:145.

2. Ozkinay FF, Akisü M, Kültürsay N, Oral R, Tansug N, Sapmaz G. Agenesis of the corpus callosum in Schinzel-Giedion syndrome associated with 47, XXY karyotype. Clin Genet. 1996;50:145-8.

3. Hoffman TL, Vossough A, Ficicioglu C, Visootsak J. Brain magnetic resonance imaging findings in 49, XXXXY syndrome. Pediatr Neurol. 2008;38:450-3.

4. Wade BS, Joshi SH, Reuter M, et al. Effects of sex chromosome dosage on corpus callosum morphology in supernumerary sex chromosome aneuploidies. Biol Sex Differ. 2014;5:16.

5. Skakkebæk A, Gravholt CH, Rasmussen PM, et al. Neuroanatomical correlates of Klinefelter syndrome studied in relation to the neuropsychological profile. Neuroimage Clin. 2014;4:1-9.

Publisher's Note Springer Nature remains neutral with regard to jurisdictional claims in published maps and institutional affiliations. 